EPJ Web of Conferences 45, 01116 (2013)

DOI: $10.1051 /$ epjconf/20134501116

(C) Owned by the authors, published by EDP Sciences, 2013

\title{
Experimental Study of Injection Characteristics of a Multi-hole port injector on various Fuel Injection pressures and Temperatures
}

\author{
E. Movahednejad ${ }^{1}$, F. Ommi ${ }^{2}$, K. Nekofar ${ }^{3}$ \\ ${ }^{1}$ Islamic Azad University, Jolfa International Branch, Jolfa, Iran \\ ${ }^{2}$ Tarbiat Modares University, Tehran, Iran \\ ${ }^{3}$ Islamic Azad University, Chaloos Branch, Iran
}

\begin{abstract}
The structures of the port injector spray dominates the mixture preparation process and strongly affect the subsequent engine combustion characteristics over a wide range of operating conditions in port-injection gasoline engines. All these spray characteristics are determined by particular injector design and operating conditions. In this paper, an experimental study is made to characterize the breakup mechanism and spray characteristics of a injector with multi-disc nozzle (SAGEM,D2159MA). A comparison was made on injection characteristics of the multi-hole injectors and its effects on various fuel pressure and temperature. The distributions of the droplet size and velocity and volume flux were characterized using phase Doppler anemometry (PDA) technique. Through this work, it was found that the injector produces a finer spray with a wide spray angle in higher fuel pressure and temperature.
\end{abstract}

\section{INTRODUCTION}

It has been known that spray atomization and targeting have a great impact on engine performance and exhaust hydrocarbon emissions. For port fuel injection engines, mixture formation process starts with the injection of liquid fuel into the intake ports. The spray introduced can be defined by its mean droplet sizes, initial velocity, spray pattern, and targeting. The fuel droplets interact with the air inside the intake manifolds, as well as intake port walls and intake valves, creating fuel vapor and wall films. All spray characteristics are determined by particular injector design and operating conditions $[1,2]$. Many spray parameters including fuel metering, atomization characteristics, targeting, and pulse-to-pulse variability have a direct impact on engine performance [3]. An optimized spatial fuel distribution plays a key role in reducing fuel wall attachment and thus, improving engine transient response and reducing hydrocarbon (HC) emissions, which is greatly determined by injector design and intake port geometry. A better understanding of spray characteristics of port injector is very important in matching spray parameters with different engine operations. As a result, there is an explosive increase of research publications in port injector sprays [4-8]. The spray atomization mechanism at different back pressures, namely ambient pressure was investigated [9]. It was found that when the liquid fuel is injected into the ambient with a back pressure below that of the equilibrium pressure, i.e., the saturated vapour pressure, the atomization process is enhanced markedly due to flash boiling vaporization phenomena.

In a study of the spray breakup of a regular and an airshrouding injector, the global spray structures from these two types of port injectors were visualized under steady and transient conditions over different fuel injection pressures $[2,3]$. The results showed the importance of agreement between spray characteristics and engine parameters.

To prepare fuel for combustion, liquid fuel must evaporate and form a fuel-air combustible mixture. Reducing spray Sauter Mean Diameter (SMD), in general, will improve the evaporation process because of increased overall surface area. On the other side, creation of the wall film will degrade the emission performance in general, and therefore it is not desired in most of the applications. The fuel is injected into the intake port through an orifice type injector. The major components of such injector consist of valve body, solenoid coil, armature, seal needle, valve seat, and orifice. Figure 1 shows the schematic of a fuel injector. A multi-disc nozzle is presented and studied in the current work. 


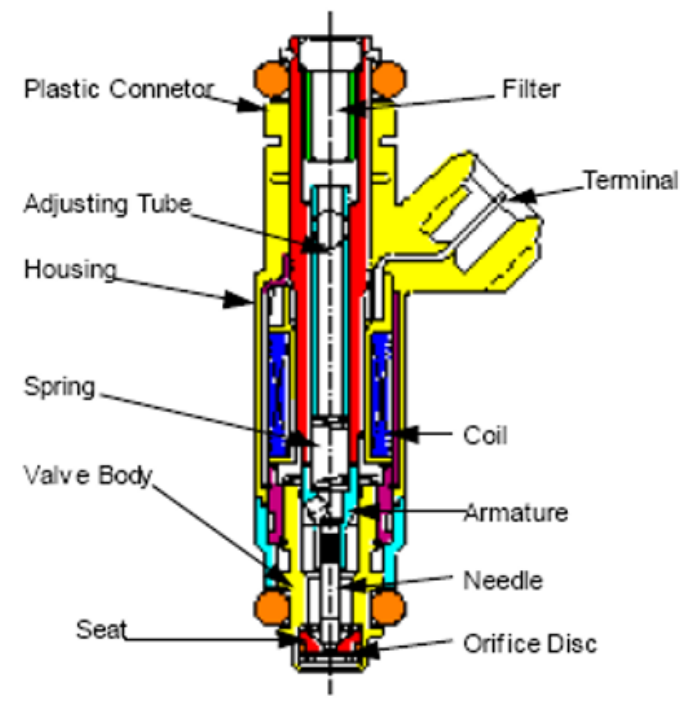

Fig. 1. Schematic of a Port Fuel Injector [1]

This paper reports an experimental study of the spray breakup and injection characteristics of a injector with Triple-Disc nozzle for applications to 8-valve Multi-point fuel injection engines. The global spray structure from this injector was measured under steady conditions over different fuel injection pressures and fuel temperatures and characterized using phase Doppler anemometry (PDA) technique. As a result, predictions are obtained that provide detailed picture of the air-fuel mixture properties along the intake port [10].

The injector has a multi-disc nozzle. Figure 2 shows the schematic of studied nozzles. The design consists of three discs. The first disc contains six narrow holes. Its primary functions are feeding the fuel to the cavity and eliminating the influence of needle-seat valve on spray targeting. The second part that is a hollow disc with edges in internal radius that creates the cavity necessary for turbulence generation. The third disc functions as a metering member, and has one straight hole. In this injector once the valve opens, the main flow of fuel passes nozzle, impinges on a plate with three holes, and separates into three jets. Figure 3 shows the visualization results of the spray caused by a multi-hole baseline compound injector which has three square exit metering holes for producing three spray jets.

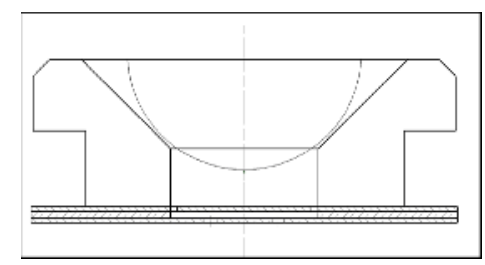

Fig. 2. Schematic of Studied Nozzle[1]
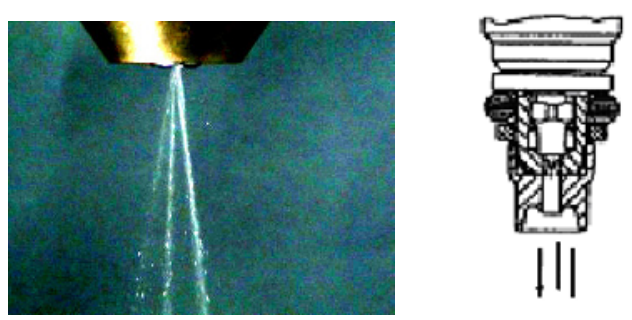

Fig. 3. Schematic of the multi-hole nozzle spray

\section{EXPERIMENTAL TECHNIQUE}

The experimental technique used in this work is a laser base technique. To obtain the detailed quantitative information of the spray, a two-component Phase Doppler Anemometry (PDA) was used to perform the simultaneous measurements of the droplet velocity and size and the volume flux. Figure 4 shows the schematic of experimental setup. A $70 \mathrm{~mW}$ laser beam is used. The receiver lens has a focal length of $600 \mathrm{~mm}$. This combination results in a measurable droplet size range of 0.5 to $1000 \mu \mathrm{m}$ and velocity range of 0 to $500 \mathrm{~m} / \mathrm{s}$. The injector was mounted at $100 \mathrm{~mm}$ above the laser beam. All measurements were done for 15 seconds and for maximum 1500 droplets. All tests were performed under atmospheric condition. As indicated in Figure 4, all spray droplet sizes were measured at $100 \mathrm{~mm}$ downstream.

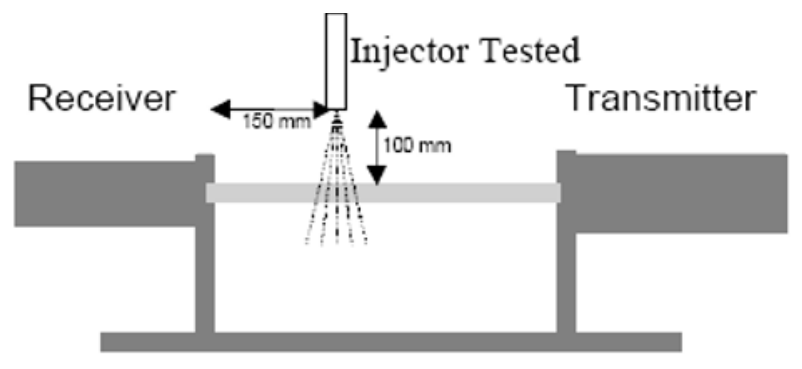

Fig. 4. Schematic of Test Setup

This ensured repeatable results for spray characteristics. Water was used to feed the injector for visualizing the spray breakup and atomization process. The fuel injection pressure and fuel temperature were changed in the range of 200 to $500(200,300,400$, and 500$) \mathrm{kPa}$ and in the range of 25 to $70^{\circ} \mathrm{C}$; respectively. Considering difference between physical properties of water and gasoline (table 1), correction factors can be used to convert the measured results for water to gasoline.

The correction factor of droplet diameter calculate using experimental Eq. 1 [11].

$$
\frac{d m}{d c}=\frac{47.8}{A^{0.6} \Pi^{0.1} \operatorname{Re}^{0.7}}
$$

A is the geometry factor that depends to geometrical characteristics of nozzle and Re is Reynolds number. 


$$
\begin{aligned}
& \mathrm{Re}=\frac{W d_{e}}{v} \\
& \Pi=\frac{\mu^{2}}{\rho \sigma d_{c}}
\end{aligned}
$$

Table 1. Thermo Physical Properties of Fuel and water

\begin{tabular}{|c|c|c|}
\hline Formula & $\mathrm{H} 2 \mathrm{O}$ & $\mathrm{C} 7.3 \mathrm{H} 13.9$ \\
\hline Surface tension $(\mathrm{N} / \mathrm{m})$ & $72.7 \times 10^{-3}$ & $20 \times 10^{-3}$ \\
\hline Vapor pressure $(\mathrm{kPa})$ & & 50 \\
\hline Viscosity $(\mathrm{N} . \mathrm{s} / \mathrm{m} 2)$ & $959 \times 10^{-6}$ & $450 \times 10^{-6}$ \\
\hline Density $(\mathrm{kg} / \mathrm{m} 3)$ & 998 & 750 \\
\hline Boiling temperature $(\mathrm{K})$ & 373 & 340 \\
\hline
\end{tabular}

Diameter and Velocity correction factors are gained according physical properties of water and gasoline (table 1), that are:

$$
\begin{aligned}
\frac{d m_{\text {fuel }}}{d m_{\text {water }}} & =0.502 \\
\frac{W_{\text {fuel }}}{W_{\text {water }}} & =1.15
\end{aligned}
$$

\section{3. the INJECTION CHARACRERISTICS INVESTIGATION}

Droplet vertical velocity distribution at $100 \mathrm{~mm}$ downstream, for $\mathrm{P}=300 \mathrm{kPa}$ and $\mathrm{T}=25{ }^{\circ} \mathrm{C}$, is shown in Figure 5. There are three high velocity zones that represent three separate jets in spray pattern as it is seen in Figure 5. The average value of more powerful jet is about two times of weaker ones.

Figure 6 shows mean diameter distribution of droplets in micron. According this figure, droplets with less mean diameter are placed in centre of the spray cone and the diameter increases along radius. Figure 7 shows the variation of droplets mean diameter along the injection axis for water with $300 \mathrm{kPa}$ and $25{ }^{\circ} \mathrm{C}$. As it is shown, at first breakup phenomena produce small droplets along the jet axis $[12,13]$ and after a reduction in drop size, the mean diameter of droplets increase because of the collision phenomenon.

\section{THE EFFECT OF FUEL INJECTION PRESSURE}

The water injection pressure was changed in the range of 200 to $500 \mathrm{kPa}$. According EQ. 6, the fuel velocity in nozzle outlet have a direct relation with $\Delta P^{0.5}$.

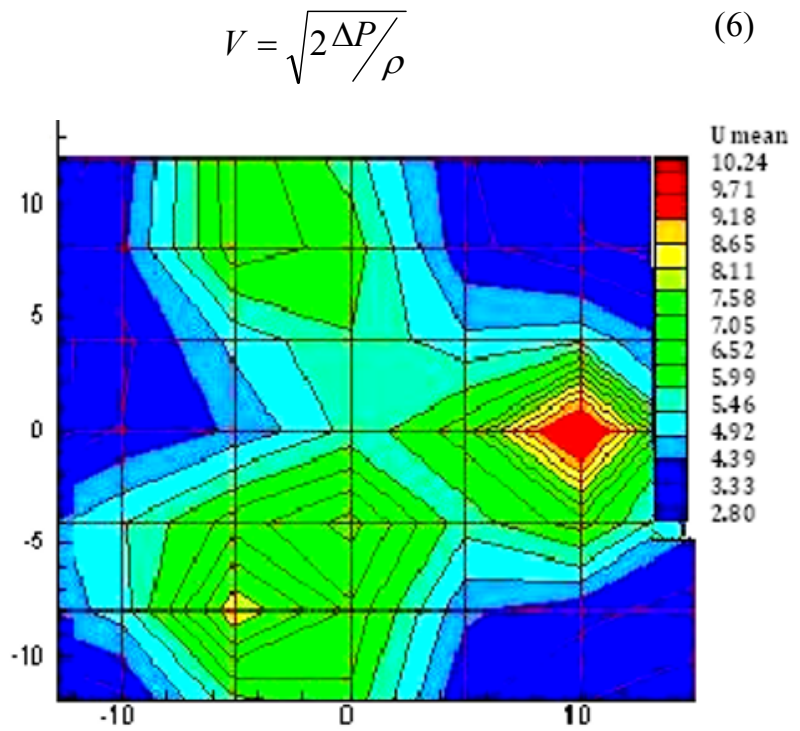

Fig. 5. Distribution of droplets velocity $(\mathrm{m} / \mathrm{s})$ in $100 \mathrm{~mm}$ downstream and $300 \mathrm{kPa}, 25^{\circ} \mathrm{C}$

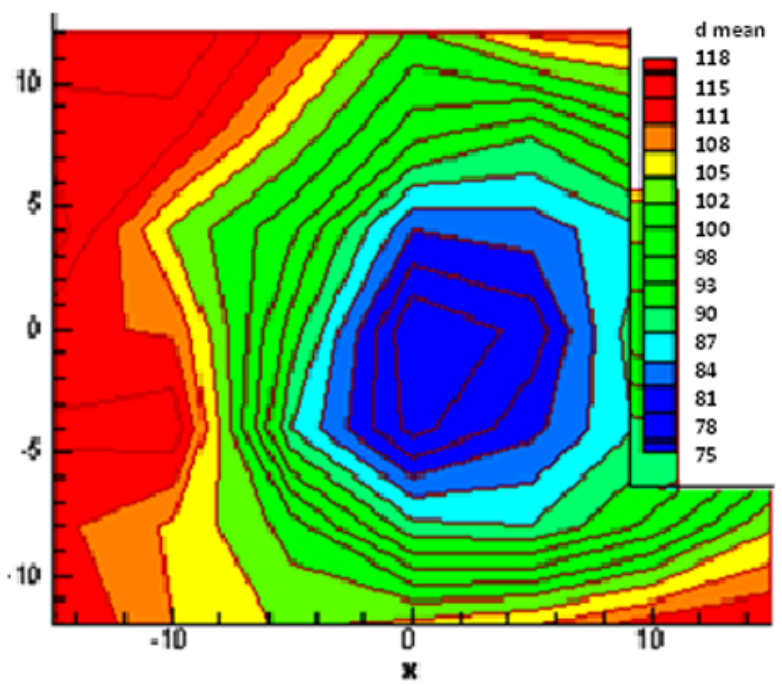

Fig. 6. Mean diameter distribution of droplets (micron) in $300 \mathrm{kPa} 25^{\circ} \mathrm{C}$

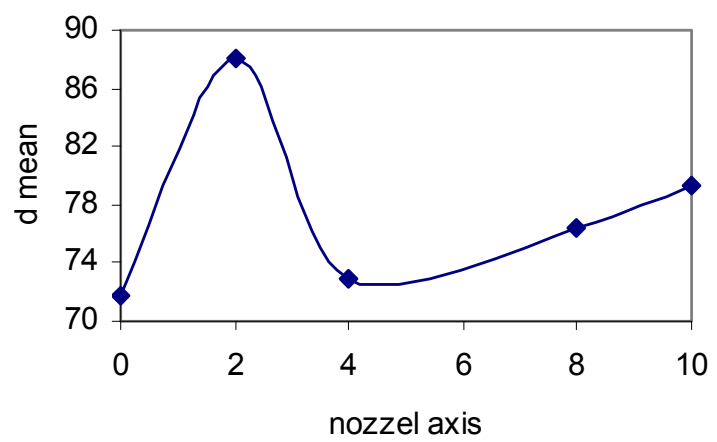

Fig. 7. Variation of droplets mean diameter along the injection axis in $300 \mathrm{kPa}$ and $25^{\circ} \mathrm{C}$

According Eq. 7 for droplet diameter, an increase in the relative velocity of droplet cause a reduction in the droplet diameter. 


$$
D_{c r i t}=\frac{8 \sigma}{C_{D} \rho_{a} U_{R}^{2}}
$$

UR and $\sigma$ are the relative velocity and the surface tension of droplet respectively.

So as the fuel pressure increases in the upper hand of the injector, both jet velocity and spray cone angle increase and as a result it makes the diameter of droplets much smaller so a better atomization is achieved. Figure 8 shows the effect of injection pressure on spray cone angle.
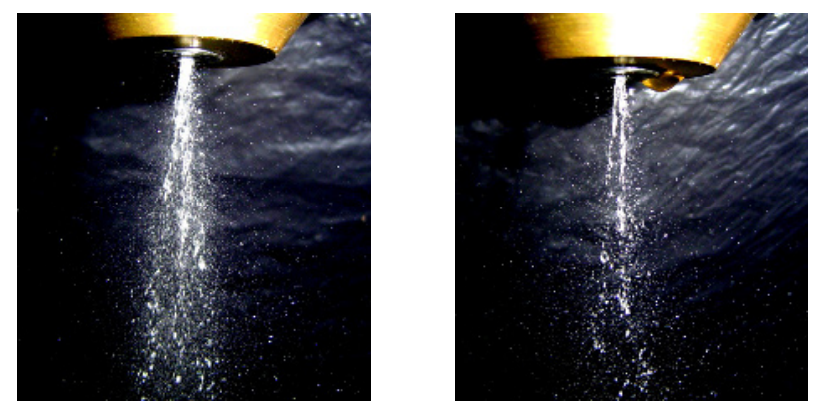

Fig. 8. the effect of injection pressure on spray cone angle (Right: 2 bar, Left: 4 bar)

It can be seen that at low injection pressure, there are three apparent separate thin liquid jets emerging from each of the exit holes. Each liquid jet propagates wavy, then breaks up into short liquid threads and blob and finally they break up into fine droplets. The liquid jet run out of the injector as a shorter continuous spray and quickly breaks up into many large droplets. At low injection pressure, the spray doesn't disperse at all. With the increase in the injection pressure, three-lobe structure quickly disappears. There is no significant azimuthally variations downstream due to the increase in the volume of each spray and enhancing effect of the atomization. With the increase in the injection pressure, there is a very slight increase in the spray angle but not so remarkable.

The injection parameters e.g. the mean diameter (SMD), the velocity and spray cone angle in different temperatures were specified. These results are shown for different fuel temperatures for nozzle outlet in table 2 .

Table 2. injection char. in various fuel pressures for $25^{\circ} \mathrm{C}$

\begin{tabular}{|c|c|c|c|c|}
\hline Fuel pressure $(\mathrm{kPa})$ & $\mathbf{2 0 0}$ & $\mathbf{3 0 0}$ & $\mathbf{4 0 0}$ & $\mathbf{5 0 0}$ \\
\hline $\begin{array}{c}\text { Initial mean velocity } \\
(\mathrm{m} / \mathrm{s})\end{array}$ & 11.9 & 13.1 & 14 & 16.1 \\
\hline $\begin{array}{c}\text { Sautre Mean diameter } \\
(\text { Micron })\end{array}$ & 81 & 77 & 74.3 & 71.5 \\
\hline Injection rate $(\mathrm{kg} / \mathrm{hr})$ & 6.99 & 8.39 & 9.9 & 11.3 \\
\hline Spray cone angle & 11 & 15 & 20 & 24 \\
\hline
\end{tabular}

Figure 9 shows the variation of droplets mean diameter in different injection pressures along the injection cross section. An increase in injection pressure from 3 bar to 5 bar, cause a reduction in the droplets mean diameter around $13 \%$.

The frequency diagram of droplets diameter is so important in investigation of injection structure and its characteristics. This diagram is shown for specified injector in fluid pressures 3 bar and 5 bar in figures 10-a and $10-\mathrm{b}$ respectively. As it is shown, maximum percent of droplets have a diameter in the range of 88 to 91 micron for fuel pressure 2 bar. This range is 77 to 80 micron for fuel pressure 5 bar.

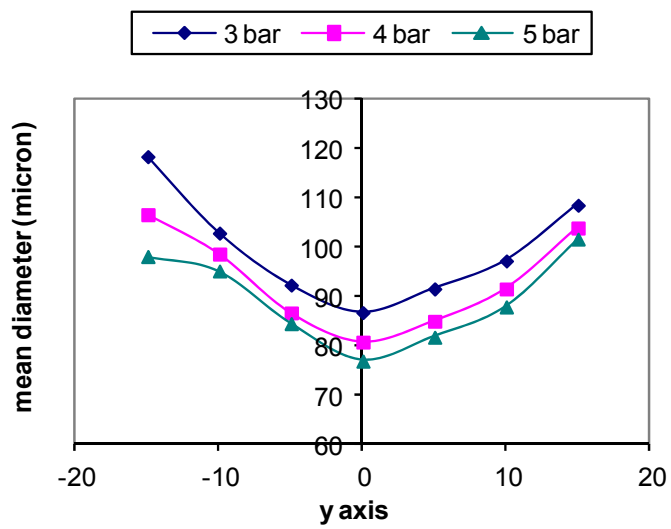

Fig. 9. variation of droplets mean diameter in different injection pressures along the injection cross section

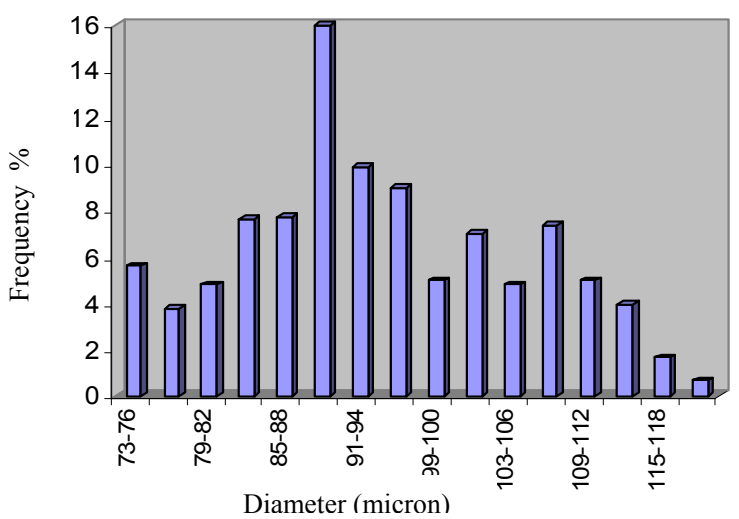

Fig. 10-a. Droplets size distribution for fuel pressure 2 bar

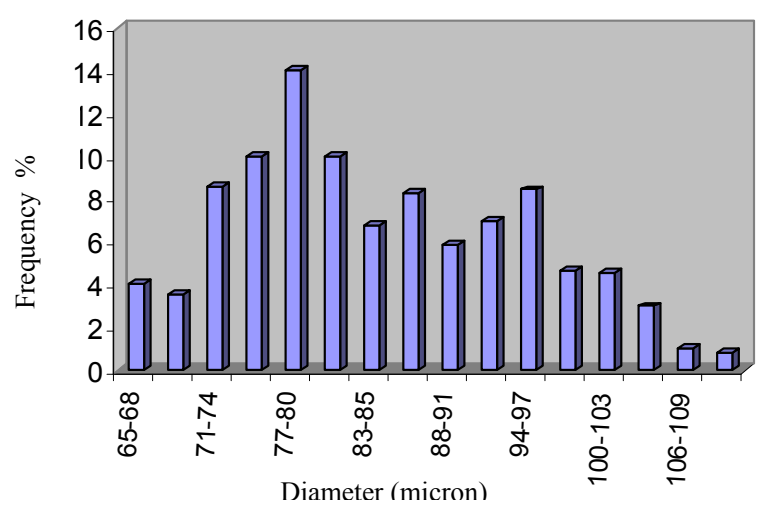

Fig. 10-b. Droplets size distribution for fuel pressure 5 bar

So increasing injection pressure has following results:

1. Increasing vaporization rate in case of relative velocity increase of fuel injection. 
2. Reduction in droplets mean diameter and increase of droplets surface contact that makes much vaporization rate.

3. Increasing the spray cone angle that provides wider spray angle (more dispersion) and much fuel wetted surface in the intake port.

4. Reducing the in hand time for fuel vaporization in the port and cylinder because of thinner injection pulse width.

\section{FUEL TEMPERATURE EFFECT}

The water injection pressure was changed in the range of 25 to $60^{\circ} \mathrm{C}$. As the fluid temperature increases, the fuel vapor pressure on the droplets and fuel film surface increases. According to Eq. 8 vapor generation rate of fuel is directly related to the saturated fuel pressure, therefore the fuel temperature increases the rate of droplets vaporization via convection and diffusion.

$$
x_{f s}=\frac{p_{s a t}\left(T_{s}\right)}{p_{\infty}}
$$

in this equation $x_{f s}$ and $p_{s a t}$ are the mass fraction of fuel vapor and saturate vapor pressure of fuel respectively.

The injection velocity of droplets in nozzle outlet for different fuel temperatures and pressure 3 bar are shown in table 3 .

Table 3. injection characteristics in various fuel temperatures for fuel pressure 3 bar

\begin{tabular}{|c|c|c|c|c|}
\hline Fuel temperature (c) & 25 & 40 & 50 & 60 \\
\hline $\begin{array}{c}\text { Initial mean velocity } \\
(\mathrm{m} / \mathrm{s})\end{array}$ & 13.2 & 14.3 & 16.7 & 21.6 \\
\hline
\end{tabular}

As it is seen, with an increase in fluid temperature from 25 to $60{ }^{\circ} \mathrm{C}$ the jet velocity increases around $60 \%$ because of reduction in surface tension and viscosity of droplets. As it is said before, the droplets diameter reduces with an increase in injection velocity.

According to the present investigation, it was found that the injector produces a finer spray in higher fuel temperatures which refine fuel-air mixture characteristics in intake port or cylinder.

\section{REFERENCES}

1. W. M. Ren, H. Sayar, SAE Technical Paper, 200101-0608 (2001)

2. F.Q. Zhao, J. H. Yoo, M. C. Lai, SAE Technical Paper, 952487 (1995)

3. F.Q. Zhao, M.C. Lai, D.L. Harrington, SAE Technical Paper, 950506 (1995)

4. W.M. Ren, H. Sayar, SAE Technical Paper, 010608 (2001)

5. M.C. Lai, F.Q. Zhao, Hiroshima, Japan, July 6-8, 79-89 (1994)
6. SAE Recommended Practice, SAE J1832, 99-115 (1989)

7. S. K. Chen, A. H. Lefebvre, J. Rollbuhler, AIAA Journal, 10-15 (1993)

8. S.D. Jackson, P. Williams, SAE Technical Paper, 961119 (1996)

9. J. Senda, T. Nishikori, T. Tsukamoto and H. Fujimoto, SAE Technical Paper, 920382 (1992)

10. E. Movahednejad, F. Ommi, M. Hossinalipour, SAE Technical Paper, 2005-01-3805 (2005)

11. Bourkaliof, F. Ommi, Sokhof, Science and Research journal of Moscow University of technology (1996)

12. E. Movahednejad, F. Ommi, Heat and Mass Transfer 47, 1591-1600 (2011)

13. E. Movahednejad, F. Ommi, S.M. Hosseinalipour, Entropy 12, 1484-1498 (2010) 